\title{
GSM-like radiofrequency exposure induces apoptosis via caspase-dependent pathway in infant rabbits
}

\author{
Meral $\mathrm{O}^{1}$, Ozgur E $\mathrm{E}^{2}$, Kismali $\mathrm{G}^{1}$, Guler $\mathrm{G}^{2}$, Alpay $\mathrm{M}^{3}$, Sel $\mathrm{T}^{1}$, Seyhan $\mathrm{N}^{2}$ \\ Department of Biochemistry, Faculty of Veterinary Medicine, Ankara University, Ankara, Turkey. \\ oguncmeral@yahoo.com
}

\begin{abstract}
BACKGROUND: There have been several Radio Frequency (RF) field researches on various populations and groups of different ages in recent years. However, the most important group for research has been declared as the pregnant women and their babies.

OBJECTIVE: The aim of the study was to analyse the effect on apoptotic factors of RF fields on newborn rabbit liver tissues.

MATERIALS AND METHODS: Cytochrome $c$ and AIF (Apoptosis Inducing Factor) levels were measured by western blot and caspase 1,3 and 9 activities were measured by colorimetric method

RESULTS: Cytochrome $c$ and AIF levels were not altered, but all caspase activities were increased in female infant rabbits that exposed to $1800 \mathrm{MHz}$ GSM-like RF signals when they reached 1 month of age and caspase 1 and caspase 3 levels were decreased in male infant rabbits that exposed to $1800 \mathrm{MHz}$ GSM-like RF signals between 15th and 22nd days of the gestational period. Results showed that $1800 \mathrm{MHz}$ GSM-like RF exposure might lead to apoptosis in infant rabbit's liver tissues.

CONCLUSION: According to the results, we suggest that postnatal RF exposure causes caspase dependent apoptosis in female infant rabbits liver tissues (Tab. 1, Fig. 2, Ref. 27). Text in PDF www.elis.sk.

KEY WORDS: radiofrequency, apoptosis, caspase, cytochrome c, rabbit.
\end{abstract}

\section{Introduction}

The technologic progress of wireless communication and cell phones causes a wide spread use of these technologies and has led to increased interest of public, government and scientific attention because of the adverse effects of the radiofrequency (RF) electromagnetic exposure (1). There's no doubt that degraded ecosystems, contaminated water, polluted indoor and outdoor air, lack of adequate sanitation, toxic hazards, disease vectors and ionizing and non-ionizing radiations are all important environmental risk factors for children therefore in developed countries there is a big interest in the maternal and neonatal health. Radiofrequency radiation (RFR), which is produced by wireless and cell phone services is one of the important environmental risk factor (2). However, in general, population vulnerable individuals such as: children, elderly people and especially pregnant women are exposed to the same degree of RFR, which is known to have an adverse health effects. RFR exposure during pregnancy may in-

${ }^{1}$ Department of Biochemistry, Faculty of Veterinary Medicine, Ankara University, Ankara, Turkey, ${ }^{2}$ Department of Biophysics and Gazi NonIonizing Radiation Protection Centre, Gazi University Medical Faculty, Ankara, Turkey, and ${ }^{3}$ Department of Biochemistry, Faculty of Medicine, Düzce University, Düzce, Turkey

Address for correspondence: $\mathrm{O}$. Meral, $\mathrm{PhD}$, Ankara University, Faculty of Veterinary Medicine, Department of Biochemistry, Irfan Bastug Cad. Diskapi 06110, Ankara, Turkey.

Phone: +90.312 .3170315$ teract with the embryo/foetus and as a result of this, abnormalities and mutations may occur (3).

$1800 \mathrm{MHz}$ frequency band is used in the former and the new technologies of Global System for Mobile Communication (GSM) (4). Cellular phones are one of the man-made sources of RFR and are used more by younger generation in the last decade. Increased use of cellular phones attracts the attention of the public about adverse health effects of mobile phone radiation, especially on children and sensitive people such as pregnant women and babies (2). Increased RFR exposure can induce reactive oxygen species (ROS) to modify the cellular balance (5). Studies showed that ROS can damage biomolecules like DNA and lead to apoptosis (4).

Programmed cell death, also called apoptosis, is an important biological process for living organism. Apoptosis is very important in various processes including normal cell turnover, embryonic development, proper development and functioning of the immune system, hormone-dependent atrophy and chemical-induced cell death. Apoptosis is characterized by a series of structural changes including chromatin condensation, DNA fragmentation and activation of cysteinyl aspartate-specific proteinases: the caspases (6-8).

Caspases (Cysteinyl-aspartate-specific proteinases) are family of cysteine proteases and have an important role in cells for programmed cell death called apoptosis. Their role in the apoptotic signalling network is essential. Disturbance in apoptosis pathway could lead to many diseases such as Alzheimer's disease, Huntington's disease, ischemic damage, autoimmune disorders and several forms of cancer (9). 
The aim of the present study was to evaluate the possible apoptotic effects of whole body $1800 \mathrm{MHz}$ Global System for Mobile Communications (GSM)-like RFR exposure in liver tissue of infant rabbits. The levels of apoptotic factors caspase-1, caspase-3, caspase-9 analysed by colorimetric assay, while apoptosis inducing factor (AIF) and cytochrome $\mathrm{C}$ were analysed by western blot method.

\section{Materials and methods}

\section{Animals}

A total of 72 one-month-old female and male New Zealand white rabbits were used in this study. The animals were obtained from the Laboratory Animals Breeding and Experimental Research Centre of Gazi University. The experimental protocol was reviewed and approved by the Laboratory Animal Care Committee of Gazi University (G.U.ET-06.027). Thirty-six of the rabbits were exposed to $1800 \mathrm{MHz}$ GSM-like RF radiation for $15 \mathrm{~min} /$ day during a week in the intrauterine period (between 15th and 22nd days of the gestational period when the transition from embryogenesis to organogenesis takes place) whereas others were not exposed.

After birth, all 72 infant rabbits were kept with their mothers until they reached one month of age. They were breastfed and their optimum growth was obtained during this one-month period. Baby rabbits aged one month were housed under the same conditions in a temperature and humidity-controlled room $\left(20 \pm 1{ }^{\circ} \mathrm{C}, 50 \pm 10\right.$ $\%$ relative humidity) and $14 / 16 \mathrm{~h}$ light/dark cycle conditions. The animals were provided with tap water and standard pelletized food ad libitum except during exposure periods. Only one animal was placed in each cage during each radiofrequency radiation (RFR) exposure period, because placing more than one animal in a cage could have created stress.

\section{Experimental design}

A total of 72 one-month-old female and male New Zealand white rabbits were used (Tab. 1). Thirty-six females were exposed to $\mathrm{RF}$ radiation for $15 \mathrm{~min} /$ day during 7 days, whereas 36 males were exposed to the same level of radiation for $15 \mathrm{~min} /$ day during 14 days. The day after the last exposure, baby rabbits were

Tab. 1. Experimental design.

\begin{tabular}{lccc}
\hline Groups & $\begin{array}{c}\text { Prenatal } \\
\text { Exposure }\end{array}$ & $\begin{array}{c}\text { Postnatal } \\
\text { Exposure }\end{array}$ & Sex \\
\hline Group I (Sham Exposure) & - & - & female \\
\hline Group II & + & - & female \\
\hline Group III $^{* *}$ & - & + & female \\
\hline Group IV $^{* * *}$ & + & + & female \\
\hline Group V (Sham Exposure) $^{*}$ & - & - & male \\
\hline Group VI & + & - & male \\
\hline Group VII $^{* *}$ & - & + & male \\
\hline Group VIII & & + & male \\
\hline
\end{tabular}

" Infant rabbits were exposed to $1800 \mathrm{MHz}$ GSM-like RF signals in the intrauterine (IU) period (between 15 th and 22 nd days of the gestational period) ${ }^{* *}$ Infant rabbits were exposed to $1800 \mathrm{MHz}$ GSM-like RF signals when they reached one month of age, ${ }^{* * *}$ Infant rabbits were exposed to $1800 \mathrm{MHz}$ GSM-like RF signals both in the intrauterine (IU) period (between 15th and 22nd days of the gestational period) and in the extrauterine (EU) period when they reached one month of age. anesthetized and sacrificed with ketamine $(35 \mathrm{mg} / \mathrm{kg}$, i.m.) and xylazine $(5-10 \mathrm{mg} / \mathrm{kg}$, i.m.).

Female infant rabbits were randomly divided into four groups:

Group I [Intrauterine exposure (-); Extrauterine exposure $(-)$ ]: Sham exposure, which means rabbits were exposed to 1800 MHz GSM-like RF signals neither in the intrauterine (IU) nor in the extrauterine (EU) periods.

Group II [Intrauterine exposure (+); Extrauterine exposure $(-)$ ]: Infant rabbits were exposed to $1800 \mathrm{MHz}$ GSM-like RF signals in the IU period (between 15 th and 22 nd days of the gestational period).

Group III [Intrauterine exposure (-); Extrauterine exposure $(+)$ ]: Infant rabbits were exposed to $1800 \mathrm{MHz}$ GSM-like RF signals when they reached one month of age.

Group IV [Intrauterine exposure (+); Extrauterine exposure $(+)$ ]: Infant rabbits were exposed to $1800 \mathrm{MHz}$ GSM-like RF signals both in the IU period (between 15th and 22nd days of the gestational period) and in the EU period when they reached one month of age.

Male infant rabbits were randomly divided into four groups:

Group V [Intrauterine exposure (-); Extrauterine exposure $(-)$ ]: Sham exposure, which means rabbits were exposed to 1800 MHz GSM-like RF signals neither in the intrauterine (IU) nor in the extrauterine $(\mathrm{EU})$ periods.

Group VI [Intrauterine exposure (+); Extrauterine exposure $(-)$ ]: Infant rabbits were exposed to $1800 \mathrm{MHz}$ GSM-like RF signals in the IU period (between 15th and 22nd days of the gestational period).

Group VII [Intrauterine exposure (-); Extrauterine exposure $(+)$ ]: Infant rabbits were exposed to $1800 \mathrm{MHz}$ GSM-like RF signals when they reached one month of age.

Group VIII [Intrauterine exposure (+); Extrauterine exposure $(+)$ ]: Infant rabbits were exposed to $1800 \mathrm{MHz}$ GSM-like RF signals both in the IU period (between 15th and 22nd days of the gestational period) and in the EU period when they reached one month of age.

\section{Exposure level and quality control}

GSM-like signals in $1800 \mathrm{MHz}$ frequency were formed by using a signal generator (Agilent Technologies $8648 \mathrm{C}$, $9 \mathrm{kHz}-3.2$ $\mathrm{GHz}$ ) with the integrated pulse modulation unit and horn antenna (Schwarzbeck, Doppelsteg Breitband Horn antenna BBHA 9120 L3F, 0.5-2.8 GHz). The generated power was controlled by a spectrum analyser (Agilent Technologies N9320A, $9 \mathrm{kHz}-3 \mathrm{GHz}$ ) integrated to the signal generator. The signals were amplitude modulated by rectangular pulses with a repetition frequency of 217 $\mathrm{Hz}$ and a duty cycle of $1: 8$ (pulse width $0.576 \mathrm{~ms}$ ), corresponding to the dominant modulation component of the GSM.

RFR generator provided $0.1 \mathrm{~W}(20 \mathrm{dBm})$ during the exposure period. The signal was controlled by means of the spectrum analyser connected to the signal generator, and NARDA EMR 300 and type 26.1 probe were used for measurement of the output radiation. Measurements were taken during the entire experiment and the data was saved in the computer, which was connected to the device via fibre optic cable. The evaluated data was $14 \pm 0.5 \mathrm{~V} / \mathrm{m}$. Estimated SAR value is calculated as $18 \mathrm{~mW} / \mathrm{kg}$. 
672-676

\section{Western blot analysis}

Rabbit liver tissues were harvested and homogenized gently in a Dounce tissue grinder (Wheaton) with RIPA lysis buffer (20 mM Tris PH 7.5, $150 \mathrm{mM} \mathrm{NaCl}, 1 \%$ Triton X-100, 2.5 mM sodium pyrophosphate, $1 \mathrm{mM}$ EDTA, $1 \% \mathrm{Na} 3 \mathrm{VO} 4,0.5 \mu \mathrm{g} / \mathrm{mL}$ leupeptin, 1 $\mathrm{mM}$ phenylmethanesulfonyl fluoride (PMSF)) to prepare of whole cell extracts. The lysates were centrifuged at $12,000 \times \mathrm{g}$ at $4{ }^{\circ} \mathrm{C}$ for $15 \mathrm{~min}$ and supernatant (cytosolic extract) was used. Protein concentrations were determined by a dye-metal-based colorimetric protein assay (10). Commercially available Pierce $660 \mathrm{~nm}$ protein assay reagent (Pierce/Thermo Scientific, Rockford, IL) which is not affected by the levels of the reducing agents. An equal amount (30 $\mu \mathrm{g}$ ) of protein was applied to each well and proteins were separated in a $12 \%$ sodium dodecyl sulphate polyacrilamide gel electrophoresis (SDS-PAGE). After electrophoresis proteins were transferred to PVDF membrane. Membrane were blocked with $3 \%$ non-fat dry milk. Anti-mouse (Biovision, USA) cytochrome c, and antimouse monoclonal IgG AIF (Santa Cruz Biotechnology, TX, USA) were used as a primary antibody and alkaline phosphatase conjugated anti-mouse (Invitrogen, NY, USA) was used as a secondary antibody. $\beta$-actin primary antibody (Genscript, USA) was used in loading control analysis for normalization. The signal was detected on PVDF membrane by BCIP/NBT Substrate (Invitrogen, NY, USA).

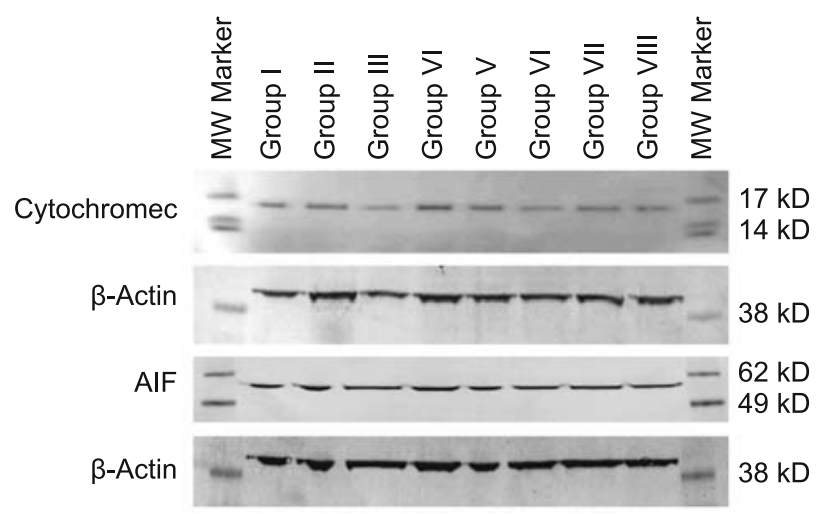

Fig. 1. Expressions of cytochrome c and AIF proteins after prenatal and postnatal GSM-Like Radiofrequency Exposure in infant rabbit liver tissues
Membranes were scanned using densitometer (Bio-Rad, GS-800) and signal intensity was determined by Quantity One Software (Bio-Rad, CA, USA) to compare expression levels among groups. Normalized three independent experiment results were done.

\section{Caspase colorimetric assays}

Caspase 1, caspase 3 and caspase 9 colorimetric assays (Biovision, CA, USA) were performed to cytosolic extract of rabbit liver tissues using Microelisa reader (Tecan, ZH, CHE) according to the manufacturer's specifications.

\section{Statistical analysis}

Statistical comparison between the RF exposed and control groups were performed using one-way ANOVA with post hoc Duncan test. P values $<0.05$ were considered statistically significant.

\section{Results}

According to the western blot analysis, expression of apoptosis regulation proteins AIF and cytochrome c levels were not significantly altered between groups. The western blot analysis results are shown in Figure 1.

Caspase results showed that caspase 1 activity was significantly increased in group III and group IV and decreased in group VI and VIII, when compared to the control. Caspase 3 activity significantly increased only in group III and decreased only in group VI when compared to the control. Caspase 9 activity significantly increased only in group III. Our data showed that all caspase activities were significantly increased in female infant rabbits group that were exposed to $1800 \mathrm{MHz}$ GSM-like RF signals when they reached 1 month of age. Also caspase 1 and caspase 3 activities were significantly decreased in male infant rabbits group that were exposed to $1800 \mathrm{MHz}$ GSM-like RF signals between 15th and 22 nd days of the gestational period. Caspase analysis results are shown in Figure 2.

\section{Discussion}

The cells of multicellular organisms are firmly regulated by controlling the rate of cell division and cell death. This process is
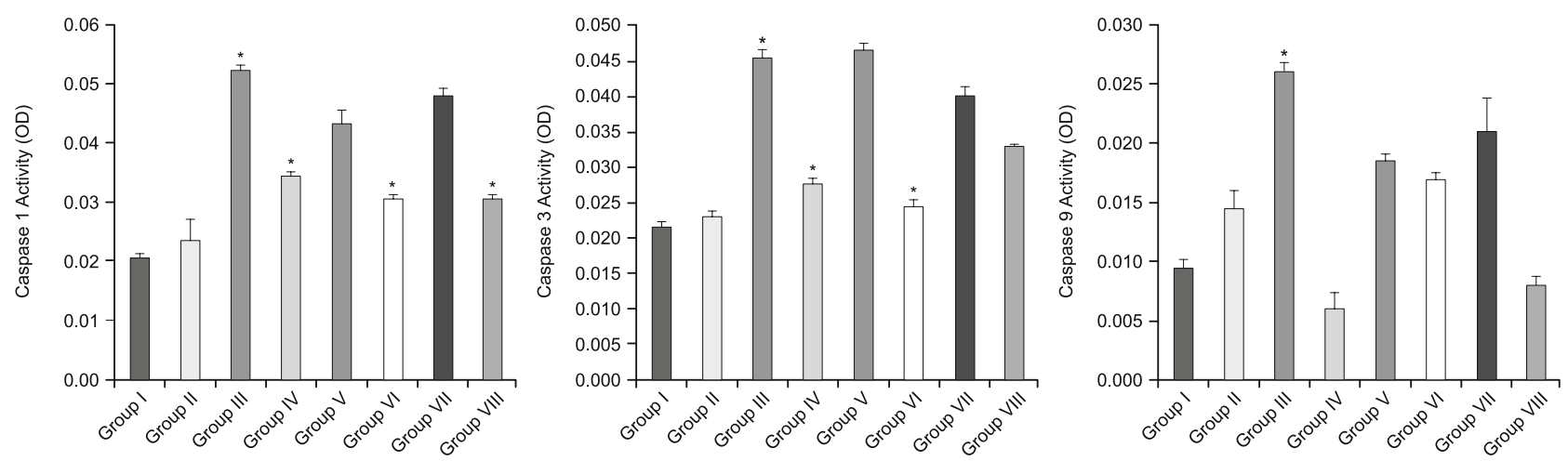

Fig. 2. Caspase 1, 3, 9 activities in infant rabbit liver tissues under prenatal and postnatal GSM-Like Radiofrequency Exposure $(* \mathbf{p}<0.05)$. 
essential for homeostasis and healthy development of all living organisms and called programmed cell death (PCD), or apoptosis. Apoptosis is also very useful for removing infected, damaged or potentially neoplastic cells from organism. However, the balance between cell division and apoptotic cell death is very important and too much or too little apoptotic cell death can lead to adverse biological effects $(11,12)$.

Apoptosis mechanism is extremely complex and in general there are two mechanisms according to whether caspases are involved or not. These pathways are known as caspase-dependent and caspase-independent pathways. Caspase- 3 and caspase- 9 usually participate in caspase dependent apoptotic pathway and apoptosis inducing factor (AIF) is the major important pro-apoptosis factor for caspase independent apoptotic pathway (13).

Apoptosis can occur through the activation of caspase dependent or caspase independent pathways. Apoptosis inducing factor (AIF) was discovered as the first caspase independent pathway mediated protein and plays an important role inducing nuclear chromatin condensation as well as large-scale DNA fragmentation $(14,15)$. In our study, no significant differences in AIF levels between the groups were observed. This finding suggested that, RF exposure might not cause apoptosis via caspase independent pathway in infant rabbit liver tissues.

In recent years there have been numerous studies about interactions between RF fields and apoptosis process. In vitro studies showed that different types of cells and different RF fields gave different results. For example, in vitro studies showed that RF fields did not induce apoptosis in lymphoblastoid cells (16), peripheral blood mononuclear cells (17), human lymphocytes (18), and yet in human epidermoid cancer cells (19) and colon cancer cells (20) apoptosis induced by RF.

In multicellular organism, a caspase dependent apoptotic pathway is initiated by cytochrome $\mathrm{c}$ release from mitochondria. As a result of this a series of reactions leads to activation of caspase 9 , then series of effector caspases like caspase 3 and finally apoptotic cell death occurs (21). However, recent studies had indicated that caspase 9 activation was also mediated by cytochrome $\mathrm{c}$ independent mechanisms (22-25). Also studies showed that apoptosis was triggered by oxidative stress (12). Ozgur et al demonstrated that postnatal RF exposure caused oxidative stress in infant female rabbits, but not in infant male rabbits (2). Also Guler et al showed that radiofrequency radiation exposure provoked apoptosis in different rabbit tissues (26). Another study performed by Yilmaz et al on rat cerebral tissues and it was pointed out that Radiofrequency radiation exposure had effect on apoptosis (27). In the present study cytochrome c levels were not altered, but different caspase levels were observed between the groups. All caspase activities were increased in female infant rabbits that exposed to $1800 \mathrm{MHz}$ GSM-like RF signals when they reached 1 month of age. In male infant rabbits that were exposed to $1800 \mathrm{MHz}$ GSM-like RF signals between 15 th and 22 nd days of the gestational period only caspase 1 and 3 levels were decreased, caspase 9 levels were not altered. These results showed that postnatal RF exposure (without prenatal) caused caspase dependent apoptosis in female infant rabbit's liver tissues.
In conclusion; the current study demonstrated the effects of prenatal and postnatal GSM-like radiofrequency exposure in infant rabbit liver tissues. We found that all caspase activities were significantly increased in female infant rabbit tissues that were exposed to $1800 \mathrm{MHz}$ GSM-like RF signals during postnatal period. According to the results, we suggest that postnatal RF exposure caused caspase dependent apoptosis in female infant rabbit's liver tissues.

\section{References}

1. Meltz ML. Radiofrequency exposure and mammalian cell toxicity, genotoxicity, and transformation. Bioelectromagnetics 2003; S6: 196-213.

2. Ozgur E, Kismali G, Guler G et al. Effects of prenatal and postnatal exposure to gsm-like radiofrequency on blood chemistry and oxidative stress in infant rabbits, an experimental study. Cell Biochem Biophys 2013; 67: 743-751.

3. Kismali G, Ozgur E, Guler G, Akcay A, Sel T, Seyhan N. The influence of $1800 \mathrm{MHz}$ GSM-like signals on blood chemistry and oxidative stress in non-pregnant and pregnant rabbits. Int J Radiat Biol 2012; 88 (5): 414-419.

4. Hou Q, Wang M, Wu S et al. Oxidative changes and apoptosis induced by $1800-\mathrm{MHz}$ electromagnetic radiation in NIH/3 3 cells. Electromagn Biol Med 2015; 34 (1): 85-92.

5. Consales C, Merla C, Marino C, Benassi B. Electromagnetic fields, oxidative stress, and neurodegeneration. Int J Cell Biol 2012; 2012: 683897.

6. Kerr JFR, Wyllie AH, Currie AR. Apoptosis: A basic biological phenomenon with wideranging implications in tissue kinetics. Br J Cancer 1972; 26: 239-257.

7. Nicholson DW, Thornberry NA. Caspases: killer proteases. Trends Biochem Sci 1997; 22 (8): 299-306.

8. Elmore S. Apoptosis: A review of programmed cell death. Toxicol Pathol 2007; 35: 495-516.

9. Cohen GM. Caspases: The executioners of apoptosis. Biochem J 1997; 326: $1-16$.

10. Antharavally BS, Mallia KA, Rangaraj P, Haney P, Bell PA. Quantitation of proteins using a dye-metal-based colorimetric protein assay. Anal Biochem 2009; 385 (2): 342-345.

11. Alberts B, Johnson A, Lewis J, Raff M, Roberts K, Walter P(Eds). Molecular biology of the cell. New York: Garland Science, 2007: 1-1464.

12. Kannan K, Jain SK. Oxidative stress and apoptosis. Pathophysiology 2000; 7 (27): 153-163.

13. Homgmei Z. Extrinsic and intrinsic apoptosis signal pathway review. 3-22. In: Ntuli TM (Eds). Apoptosis and medicine. Croatia: InTech, 2012.

14. Lu CX, Fan TJ, Hu GB, Cong RS. Apoptosis-inducing factor and apoptosis. Acta Biochim Biophys Sin 2003; 35 (10): 881-885.

15. Norberg E, Orrenius S, Zhivotovsky B. Mitochondrial regulation of cell death: Processing of apoptosis-inducing factor (AIF). Biochem Biophys Res Commun 2010; 396: 95-100.

16. Hook GJ, Zhang P, Lagroye I et al. Measurement of DNA damage and apoptosis in Molt-4 cells after in vitro exposure to radiofrequency radiation. Radiat Res 2004; 161: 193-200. 


\section{2-676}

17. Capri M, Scarcella E, Bianchi E et al. $1800 \mathrm{MHz}$ radiofrequency (mobile phones, different global system for mobile communication modulations) does not affect apoptosis and heat shock protein 70 level in peripheral blood mononuclear cells from young and old donors. Int J Radiat Biol 2004; 80 (6): 389-397.

18. Capri M, Scarella E, Fumelli C et al. In vitro exposure of human lymphocytes to $900 \mathrm{mhz}$ cw and GSM modulated radiofrequency: Studies of proliferation, apoptosis and mitochondrial membrane potential. Radiat Res 2004; 162: 211-218.

19. Caraglia M, Marra M, Mancinelli F et al. Electromagnetic fields at mobile phone frequency induce apoptosis and inactivation of the multichaperone complex in human epidermoid cancer cells. J Cell Physiol 2005; 204 (2): 539-48.

20. Maeda K, Maeda T, Qi Y. In vitro and in vivo induction of human LoVo cells into apoptotic process by non-invasive microwave treatment: A potentially novel approach for physical therapy of human colorectal cancer. Oncol Rep 2004; 11 (4): 771-775.

21. Jiang $X$, Wang $X$. Cytochrome $C$-mediated apoptosis. Annu Rev Biochem 2004; 73: 87-106.

22. Bitzer M, Armeanu S, Prinz F et al. Caspase-8 and Apaf-1-independent caspase-9 activation in Sendai virus-infected cells. J Biol Chem 2002; 277 (33): 29817-29824.
23. Morishima N, Nakanishi K, Takenouchi H, Shibata T, Yasuhiko Y. An endoplasmic reticulum stress-specific caspase cascade in apoptosis. Cytochrome c-independent activation of caspase-9 by caspase-12. J Biol Chem 2002; 277 (37): 34287-34294.

24. McDonnell MA, Wang D, Khan SM, Vander Heiden MG, Kelekar A. Caspase-9 is activated in a cytochrome c-independent manner early during TNFalpha-induced apoptosis in murine cells. Cell Death Differ 2003; 10 (9): 1005-1015.

25. Hishita T, Tada-Oikawa S, Tohyama K et al. Caspase-3 activation by lysosomal enzymes in cytochrome c-independent apoptosis in myelodysplastic syndrome-derived cell line P39. Cancer Res 2001; 61 (7): 2878-2884.

26. Guler G, Ozgur E, Keles H, Tomruk A, Vural SA, Seyhan N. Apoptosis resulted from radiofrequency radiation exposure of pregnant rabbits and their infants. Bull Vet Inst Pulawy 2011; 55: 127-134.

27. Yilmaz A, Yilmaz N, Serarslan $Y$ et al. The effects of mobile phones on apoptosis in cerebral tissue: An experimental study on rats. Eur Rev Med Pharmacol Sci 2014; 18 (7): 992-1000.

Received June 21, 2016. Accepted July 2, 2016. 